\title{
Methyl jasmonate controls sprouting incidence in stored sweet potatoes and preserves overall quality for fried chips
}

\author{
Mário Leno Martins Véras ${ }^{1, \star}$ (D), Nicolas Oliveira de Araújo² (D), Mirelle Nayana Sousa Santos² (D), \\ Jean Paulo de Jesus Tello² (D), Fernanda Ferreira de Araújo² (D), Fernando Luiz Finger² (D) \\ 1. Instituto Federal do Amapá - Campus Agrícola de Porto Grande - Porto Grande (AP), Brazil. \\ 2. Universidade Federal de Viçosa - Departamento de Biologia Vegetal - Laboratório de Fisiologia Pós-Colheita - Viçosa (MG), Brazil. \\ Received: Mar. 27, 2021 | Accepted: Jul. 1, 2021 \\ Section Editor: Juliana Sanches \\ *Corresponding author: mario.veras1992@gmail.com \\ How to cite: Veras, M. L. M., Araújo, N. O., Santos, M. N. S., Tello, J. P. J., Araújo, F. F. and Finger, F. L. (2021) Methyl jasmonate controls sprouting \\ incidence in stored sweet potatoes and preserves overall quality for fried chips. Bragantia, 80, e4721. https://doi.org/10.1590/1678-4499.20210090
}

\begin{abstract}
High incidence of sprouts and loss of quality of sweet potato is one of the negative aspects that compromises the commercialization most, and the methods of sprout control are still very limited. The appearance of sprouts promotes the wilting of sweet potato roots, reducing their commercialization period. The main objectives of this study were to evaluate sprout control and physiological and biochemical changes, in addition to the impact on the quality of postharvest chips in sweet potato roots cultivar BRS Cuia treated with methyl jasmonate (MeJa) and nonanoic acid (NA). Roots were fogged with $10 \mu \mathrm{mol} \cdot \mathrm{L}^{-1} \mathrm{MeJa}$ or $5 \mu \mathrm{mol} \cdot \mathrm{L}^{-1} \mathrm{NA}$ applied at first sprout initiation and control. Physiological and biochemical alterations such as fresh weight loss assessment, sprouting incidence and sprout length, total soluble sugars, reducing sugars, nonreducing sugars, enzymatic peroxidase and polyphenol oxidase, chips quality after frying were then assessed. Besides that, to determine the influence of treatments and storage periods, multivariate analysis was also performed using the main components. The MeJa reduced the incidence of sprouting and maintained the root quality during storage at room temperature. Notably, such events led to an increased both shelf life and potential of commercialization. Moreover, MeJa-treated chips displayed lighter color appearance after frying than control and NA-treated roots. Roots fogged with NA did not suppress the growth of sprouts, which consequently triggered a higher browning intensity in fried sweet potato chips.
\end{abstract}

Key words: Ipomoea batatas, plant regulator, sprout growth, storage.

\section{INTRODUCTION}

Sweet potato is a food-root recognized as an important source of fibber and dietetics vitamins, becoming an eminent economic commodity in recent years. Because of these reasons, it has been widely cultivated by presenting high adaptation and yield under different environmental conditions (Luo et al. 2020).

Sweet potatoes are commonly stored under ambient temperature and consumed immediately after harvesting (Lee and Lee 2017). The storage at room temperature is not the most suitable way to increase the shelf life, since the elevated temperature promotes the sprouting initiation and fresh weight loss, with a display life varying from two to four weeks (Cheema et al. 2013).

Leaf sprouting triggers several metabolic changes and is one of the key causes of losses of sweet potato roots during storage, reducing their fresh weight in consequence of higher water loss through sprouting surface (Teper-Bamnolker et al. 2010). In addition, sprouting can negatively affect the commercialization of the root, causing income losses to the producers. Therefore, the use of sprout suppressors appears a suitable alternative to increase shelf life and keep roots quality (El-Sayed et al. 2013).

Either sprouting suppression or inhibition in vegetables during storage is often performed using chemicals. Their mechanism of action involves metabolic changes, as studied in potatoes (Sugri et al. 2017). Among the sprout suppressors, 
methyl jasmonate (MeJa) stands out by reducing sprouting incidence efficiently. Methyl jasmonate controls sprouting emergence and improve the quality of processing vegetables, including radishes (Pirbalouti et al. 2014; Wang 1998). In a study addressed by Wang (1998), it was observed that roots immersion in $10^{-4} \mathrm{~mol} \cdot \mathrm{L}^{-1} \mathrm{MeJa}$ significantly reduced sprouting in radish roots. However, the role of jasmonates in controlling sprouting in sweet potatoes remains unknown (Dhaif Allah et al. 2018).

Nonanoic acid (NA), also called pelargonic acid, is registered as herbicide and used for potato desiccator before harvest, which may cause necrotic lesions when applied to vegetables (Ciriminna et al. 2019). In this sense, NA can be used as a sprout suppressor in sweet potato roots, as it can desiccate them and thus reduce the sprouting percentage. However, there is a lack of studies concerning NA as a sprout suppressor in sweet potatoes.

High incidence in sprouting is a related problem in the postharvest that compromises the commercialization of the roots. So, the main objectives of this study were to evaluate sprout control and physiological and biochemical changes, in addition to the impact on the quality of postharvest chips in sweet potato roots cultivar BRS Cuia treated with MeJa and NA.

\section{MATERIAL AND METHODS}

This study was performed at the Experimental Facilities from Departamento de Fitotecnia, Universidade Federal de Viçosa (UFV), Viçosa, Minas Gerais, Brazil (2045’20" S and 42 $52^{\prime} 40^{\prime \prime}$ W, 651 m altitude), from September 2017 to February 2018 timeframes, namely as spring planting.

Seedlings of sweet potato cultivar BRS Cuia (Frutplan Ltda) were set out in a spacing of $1.0 \mathrm{~m}$ (between ridges) $\times 0.4 \mathrm{~m}$ (between plants). The cultivation ridges were arranged in $10 \mathrm{~m}$ long by $0.30 \mathrm{~m}$ high. Soil management was performed in a conventional way by using disc plow and harrow. The fertilization was carried out according to the soil chemical analysis and technical recommendations as follows: liming for planting with $100 \mathrm{~g} \cdot \mathrm{m}^{-2}$ of limestone; planting fertilization with $100 \mathrm{~g} \cdot \mathrm{m}^{-2}$ of NPK 8-28-16; growth fertilization with $50 \mathrm{~g} \cdot \mathrm{m}^{-2}$ of NPK 8-28-16 every 30 days. The irrigation was carried out by a sprinkler system under continuous activity.

The harvest was performed at 130 days after planting when roots had weigh between 300 to $600 \mathrm{~g}$, free of diseases and damage and immediately transported in plastic boxes. At the laboratory, the roots were submitted to the curing process at $30{ }^{\circ} \mathrm{C}$ and relative humidity $90 \%$ for 7 days (Amoah et al. 2016) in manufactured biochemical oxygen demand (BOD) incubator (Thermolab Scientific Equipments).

Sweet potato roots cultivar BRS Cuia were stored in chambers at $25{ }^{\circ} \mathrm{C}$ until breaking dormancy. After sprouting emergence, the roots were submitted to either $10 \mu \mathrm{mol} \cdot \mathrm{L}^{-1} \mathrm{MeJa}$ (Dhaif Allah et al. 2018) or $5 \mu \mathrm{mol} \cdot \mathrm{L}^{-1} \mathrm{NA}$. The application was accomplished via vaporization, as described elsewhere (Vaughn and Spencer 1991).

The roots were placed in $90 \mathrm{~L}$ chambers, containing inside a Petri dish on a hot plate with solutions of either MeJa or NA diluted in $3 \mathrm{~mL}$ of ethanol 95\%. Each hot Petri dish was filled with a filter paper containing $10 \mu \mathrm{mol} \cdot \mathrm{L}^{-1} \mathrm{MeJa}$ and $5 \mu \mathrm{mol} \cdot \mathrm{L}^{-1}$ NA for each $1 \mathrm{~kg}$ of sweet potato. After $2 \mathrm{~h}$ of conditioning, the roots were stored on a bench at ambient temperature \pm $25{ }^{\circ} \mathrm{C}$ and relative humidity $\pm 90 \%$. Control roots were treated with vaporization of the $95 \%$ ethanol solution during the same period.

Samples were collected from each treatment at 0, 10, 20,30, and 40 days after storage. Five replications were used, each repetition consisting of three roots. They were then evaluated for fresh weight loss, sprout percentage, sprout length, total soluble sugars, reducing sugars, nonreducing sugars, alcohol insoluble solids, peroxidase, and polyphenol oxidase activity, root emergence and chips browning intensity after frying.

During storage, sweet potato roots were weighed on an analytical balance and the results were expressed as a percentage of fresh weight loss, as follows (Eq. 1):

$$
\mathrm{FWL}=\frac{\mathrm{W}_{0}-\mathrm{W}_{\mathrm{f}}}{\mathrm{W}_{0}} \times 100
$$

where FWL, fresh weight loss (\%); $\mathrm{W}_{0}$, initial fresh weight $(\mathrm{g})$; and $\mathrm{W}_{\mathrm{f}}$ final fresh weight $(\mathrm{g})$. 
Sprouting incidence was determined based on the number of sprouts, the values being calculated with the highest number of sprouts set to $100 \%$ (Santos et al. 2020). Sprout length was accomplished by a digital caliper, with the data expressed in millimeter.

Approximately $5 \mathrm{~g}$ of fresh pulp samples were macerated and homogenized in $80 \%$ ethanol heated to $85^{\circ} \mathrm{C}$. Subsequently, the extract was centrifuged at 13,000 g for 10 min to separate the supernatant. This step was repeated twice with $80 \%$ ethanol. This extract was used for carbohydrate analysis (total soluble sugars [TSS] and reducing sugars [RS]).

Total soluble sugars were quantified by the phenol-sulfuric method (Dubois et al. 1956). It was collected $0.25 \mathrm{~mL}$ of the supernatant, $0.25 \mathrm{~mL}$ of $5 \%$ phenol solution, and $1.25 \mathrm{~mL}$ of sulfuric acid $\left(\mathrm{H}_{2} \mathrm{SO}_{4}\right)$. The mixer was then incubated at $30{ }^{\circ} \mathrm{C}$ for $20 \mathrm{~min}$. After cooling, the samples were read at $490 \mathrm{~nm}$. The observed optical density was fitted in a standard sucrose curve $(0-50 \mu \mathrm{g})$ and the TSS content was expressed as \% TSS on a fresh weight basis.

Reducing sugars were quantified in accordance with dinitrosalicylic acid (DNS) method (Gonçalves et al. 2010). A $0.5 \mathrm{~mL}$ aliquot of supernatant and $0.5 \mathrm{~mL}$ DNS were added to tubes and incubated in a water bath until boiling. After cooling, $4 \mathrm{~mL}$ of water was added to the tubes, being followed by reading at $540 \mathrm{~nm}$. The RS content was expressed in \% RS, on a fresh weight basis, assessed by a standard curve of fructose $(0-1.0 \mathrm{mg})$. Nonreduced sugar (NRS) content was determined by the difference between TSS and RS, being expressed in \% NRS on a fresh weight basis.

For peroxidase (POD) extraction, $0.2 \mathrm{~g}$ samples of bark were homogenized in extraction buffer containing $0.1 \mathrm{~mol} \cdot \mathrm{L}^{-1}$ phosphate buffer ( $\mathrm{pH}$ 6.5). Peroxidase activity assay was performed based on Kar and Mishra (1976). The reaction buffer consisted of $25 \mathrm{mmol} \cdot \mathrm{L}^{-1}$ potassium phosphate ( $\mathrm{pH}$ 6.5), $20 \mathrm{mmol} \cdot \mathrm{L}^{-1}$ guaiacol and $20 \mathrm{mmol} \cdot \mathrm{L}^{-1} \mathrm{H}_{2} \mathrm{O}_{2}$. Activity was determined by the increase of absorbance at $470 \mathrm{~nm}$ and expressed in $\mathrm{mmol} \cdot \mathrm{s}^{-1} \cdot \mathrm{kg}^{-1}$ protein, using the molar extinction coefficient of $26.6 \mu \mathrm{mol} \cdot \mathrm{L}^{-1} \cdot \mathrm{m}^{-1}$.

The polyphenol oxidase (PPO) activity was based on the method described by Benjamin and Montgomery (1973), where approximately $0.2 \mathrm{~g}$ of pulp was homogenized in extraction buffer containing $0.1 \mathrm{~mol} \cdot \mathrm{L}^{-1}$ potassium phosphate (pH 6.5) and $1 \mathrm{mmol} \cdot \mathrm{L}^{-1}$ phenylmethanesulfonyl fluoride (PMSF). The homogenate was centrifuged at 14,000 $\mathrm{g}$ for $15 \mathrm{~min}$ at $4{ }^{\circ} \mathrm{C}$. The reaction medium consisted of $0.1 \mathrm{~mol} \cdot \mathrm{L}^{-1}$ potassium phosphate $(\mathrm{pH} 5.0)$ and $120 \mathrm{mmol} \cdot \mathrm{L}^{-1}$ pyrocatechol. The samples were read at $420 \mathrm{~nm}$ at for $3 \mathrm{~min}$. Polyphenol oxidase activity was expressed in mmol. $\mathrm{s}^{-1} \cdot \mathrm{kg}^{-1}$ protein using a molar extinction coefficient $3,450 \mathrm{mmol} \cdot \mathrm{L}^{-1} \cdot \mathrm{m}^{-1}$ (Ögel et al. 2006).

To determine the chips color, the roots were peeled, cleaned, sliced in chips, and fried in refined soybean oil for $2 \mathrm{~min}$ at $180^{\circ} \mathrm{C}$ (Caetano et al. 2018) in a monitored fryer (Ford, Michigan, USA). For each treatment, 10 chips were used and the analysis was visually was based on a color standard for fries, as follows: 1 , chips with a lighter surface; 2 , chips with slightly darkened edges; 3 , chips with more than $50 \%$ darkened surface; and 4, chips with more than $75 \%$ darkened surface (Fig. 1).

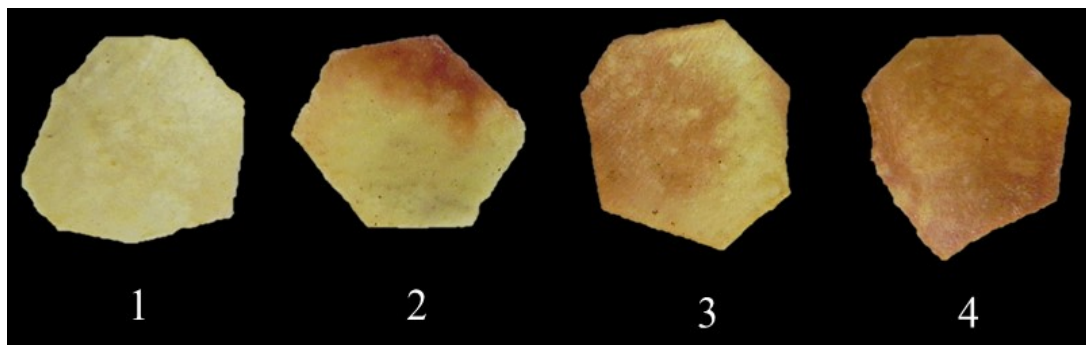

Figure 1. Color standards for analysis of fried sweet potato chips.

The experiment was conducted in a completely randomized design, arranged in a split-plot scheme, with sprout suppressors (control, $10 \mu \mathrm{mol} \cdot \mathrm{L}^{-1} \mathrm{MeJa}$ and $5 \mu \mathrm{mol} \cdot \mathrm{L}^{-1} \mathrm{NA}$ ) in the plot and the storage periods in subplot: $0,10,20,30$ and 40 days. Five replicates per treatment and three roots as an experimental unit.

The data were examined by analysis of variance using SAS software. The means were compared by Tukey's test $\mathrm{p}>0.05$. Descriptive statistics of the means based on standard error were also explored. To determine the influence of treatments and storage periods, multivariate analysis was also performed using the main components principal component analysis (PCA) using R software version 4.0.3 (R Core Team 2020). The graphics were created using the software SigmaPlot 10.0. 


\section{RESULTS AND DISCUSSION}

The roots sprouting percentage increased over time during the storage for all evaluated treatments at room temperature (Fig. 2a). However, NA-treated roots showed higher sprouting percentage during storage as compared to control and MeJa. This was observed particularly after 40 days, when there was $92.6 \%$ of sprouting (Fig. 2a). Regarding the sprout length (Fig. 2b), an increase in control roots up to 30 days of storage, when the longest shoot reached $(30.1 \mathrm{~mm})$. On the other hand, MeJa-treated roots showed shorter sprouts after 10 days when compared to the other treatments. At the end of the storage period, they presented the lowest observed value $(4.3 \mathrm{~mm})$.
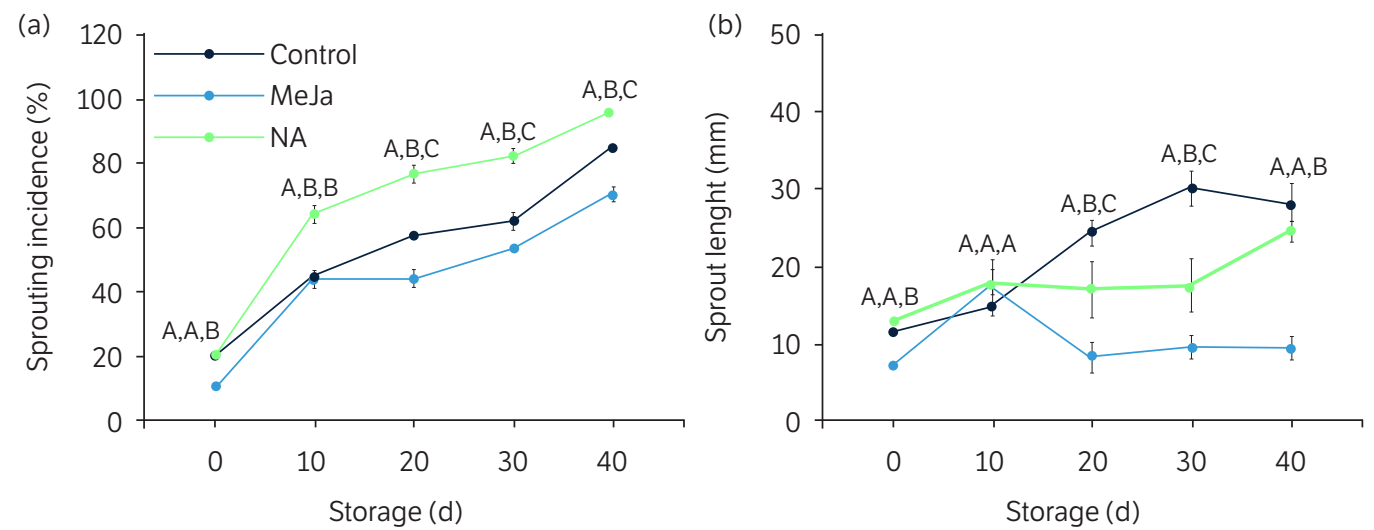

Figure 2. Sprouting incidence (a) and sprout length (b) in sweet potato roots cultivar BRS Cuia responding to the application of sprout suppressors (control, $10 \mu \mathrm{mol} \cdot \mathrm{L}^{-1} \mathrm{MeJa}$, and $5 \mu \mathrm{mol} \cdot \mathrm{L}^{-1} \mathrm{NA}$ ) during storage for 40 days at temperature of $25^{\circ} \mathrm{C}$ and relative humidity $\pm 90 \%$.

Note. The data represent the mean \pm standard error $(n=5)$. Capital letters above lines indicate differences between treatments in each storage time, according to the Tukey test at $5 \%$ probability.

The incidence of sprouts is one of the factors that influence the nonacceptance of sweet potatoes by consumers. Treatment with suppressors during the storage to keep roots overall quality has been a focus for sweet potatoes producers (El-Sayed et al. 2013). Wang (1998) highlighted that the application of MeJa inhibits sprouting in vegetables that are stored at room temperatures, especially on the commercialization stage. Moreover, other studies have reported that MeJa acts suppressing sprouting, particularly in potatoes (Platonova and Korableva 1992; Platonova et al. 2010). In the present study, likewise, the application of MeJa reduced sprouting incidence rate and prolonged root shelf life, increasing, therefore, its potential of commercialization.

Both control and NA-treated sweet potato roots showed a higher incidence of sprouting during storage compared to MeJa-treated roots. Furthermore, MeJa led to few numbers and shorted sprouts (9 mm), in sweet potato roots (Fig. 3), similar to previous works reported by Lulai et al. (1995); Platonova et al. (2010), with potatoes (Solanum tuberosum L.).

Changes in carbohydrates levels were observed during the storage of sweet potato roots cultivar BRS Cuia (Fig. 4). However, MeJa-treated roots showed higher levels $(2.62 \%)$ of TSS until the $20^{\text {th }}$ day, as compared to the control and NA treatment, followed by drop until the last day of storage (Fig. 4a).

The application of NA in sweet potato roots promoted the highest accumulation of RS until the $30^{\text {th }}$ day, with $0.63 \%$. On the other hand, both control and MeJa reduced RS after 10 days of storage (Fig. 4b). Higher levels of RS are not suitable for sweet potato quality, as they can lead to browning in fried chips by accumulating dark compounds with undesirable taste. Moreover, it causes losses of visual quality, which is the main aspect of the low acceptance by consumers (Araújo et al. 2016; Kumar et al. 2004; Mckenzie et al. 2005).

Recent studies reported that the reduction in RS levels occurs due to the sprouting occurrence (Finger et al. 2018; Foukaraki et al. 2016; Jia et al. 2019). During sprouting emergence, cellular metabolism cues synthesis of reserve compounds towards degradation processes. Thus, sucrose is hydrolyzed and used as a carbon source to sprout growth and development (Hajirezaei et al. 2003). These findings are under close agreement with the behavior presented by MeJa treatment, in which the lowest sprouting percentages were observed (Fig. 2a). Consequently, higher sucrose catabolism activity (Fig. 4c) was also evidenced by the enhanced RS levels on the last day of storage (Fig. $4 \mathrm{~b}$ ). 


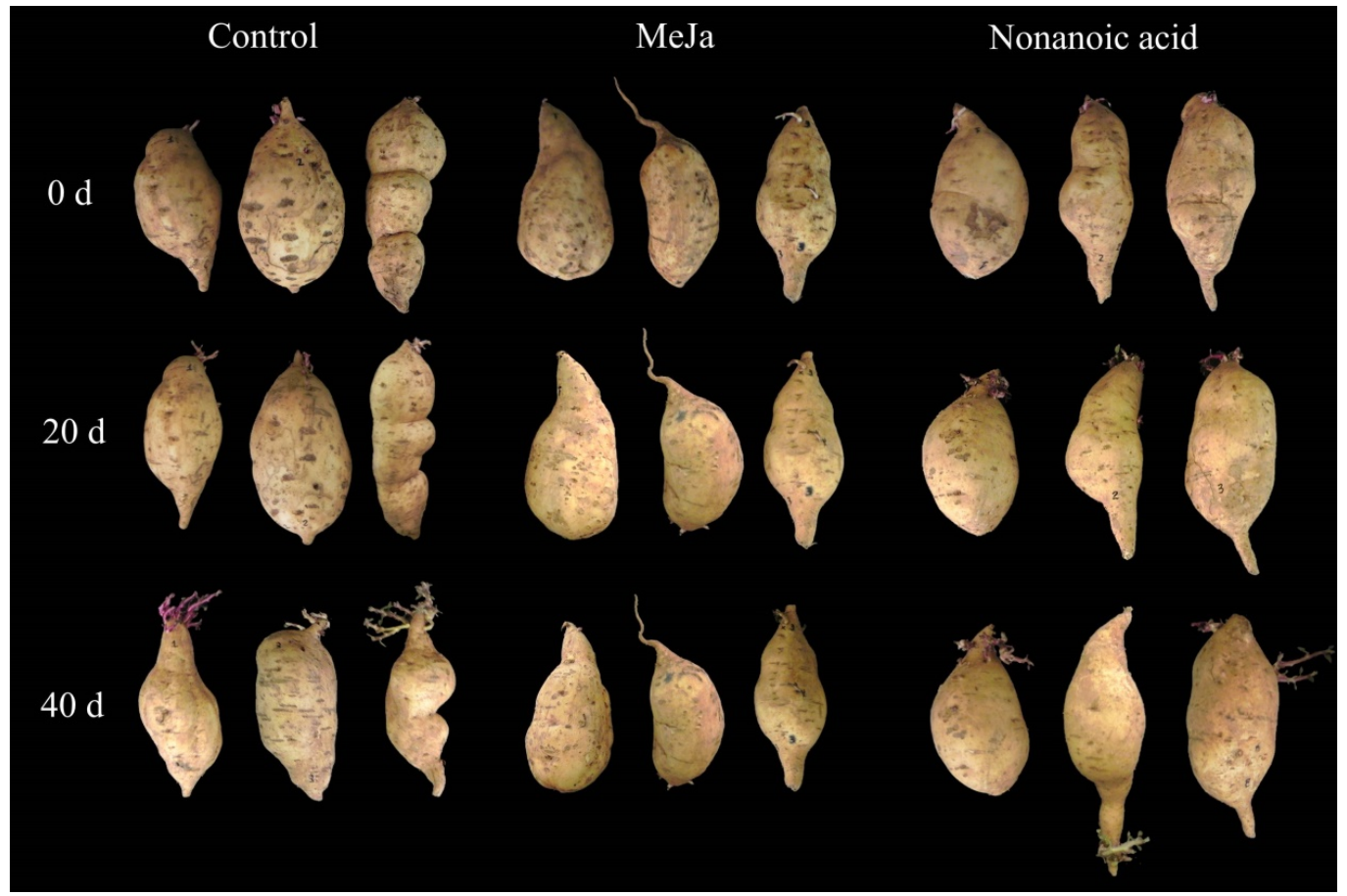

Figure 3. Visual aspects of sweet potato roots cultivar BRS Cuia, before and after storage for 40 days at $25^{\circ} \mathrm{C}$, treated with sprout suppressors $\left(10 \mu \mathrm{mol} \cdot \mathrm{L}^{-1} \mathrm{MeJa}\right.$ or $\left.5 \mu \mathrm{mol} \cdot \mathrm{L}^{-1} \mathrm{NA}\right)$, alongside with the control (without treatment).
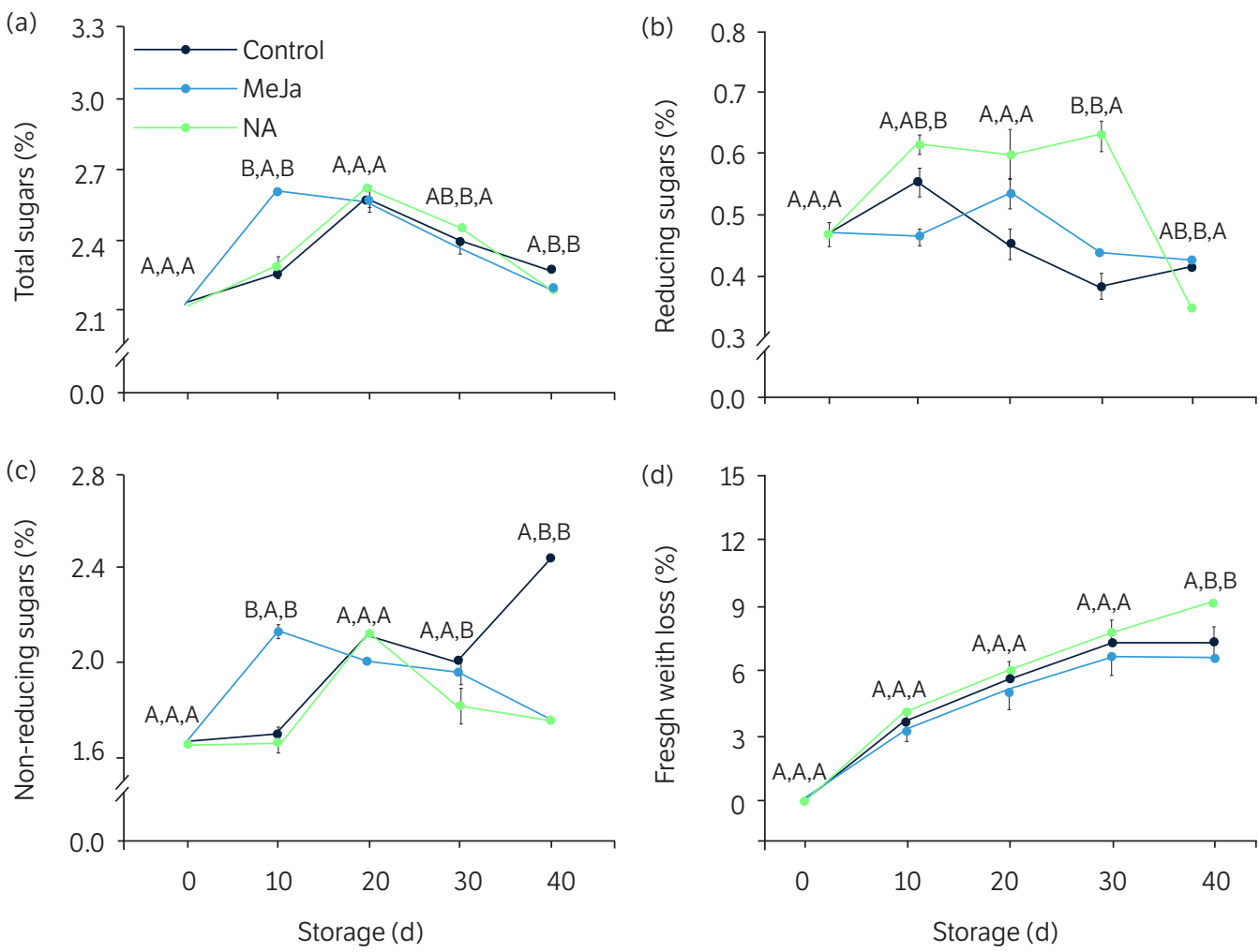

Figure 4. Total soluble sugars (a), reducing (b), nonreducing (c), and fresh weight loss (d) in sweet potato roots cultivar BRS Cuia responding to the application of sprout suppressors (control, $10 \mu \mathrm{mol} \cdot \mathrm{L}^{-1} \mathrm{MeJa}$ and $5 \mu \mathrm{mol} \cdot \mathrm{L}^{-1} \mathrm{NA}$ ) during storage for 40 days at temperature of $25{ }^{\circ} \mathrm{C}$ and relative humidity $\pm 90 \%$.

Note. The data represent the mean \pm standard error $(n=5)$. Capital letters above lines indicate differences between treatments in each storage time, according to the Tukey test at $5 \%$ probability. 
The NRS percentage fluctuated over the storage period in all evaluated treatments. However, at 40 days, control sweet potato roots showed NRS percentages 1.40 times higher than observed in MeJa and NA-treated roots (Fig. 4c).

Fresh weight loss linearly increased during storage for all treatments evaluated (Fig. 4d); however, roots treated with NA displayed the highest weight loss (9.08\%), on average, after 40 days of storage. The lowest percentage of fresh weight loss was observed in MeJa-treated roots (6.51\%).

Fresh weight loss of sweet potato roots during storage is a consequence of both water loss and respiratory activity, which increases rapidly with sprout emergence and growth. Such events prompt the senescence process, leading to a high fresh weight loss and reduced shelf life (Madonna et al. 2018; Mani et al. 2014). Dhaif Allah et al. (2018) also observed the lowest fresh weight loss in potato tubers treated with $0.01 \mathrm{mmol} \cdot \mathrm{L}^{-1} \mathrm{MeJa}$.

Regardless of the treatments, the color of sweet potato chips did not differ at the beginning of the storage period. Control and NA-treated chips showed a darker color (Fig. 5) at 20 and 40 days (Fig. 6), indicating a reduction in the quality of fried potato processing. Otherwise, MeJa-treated chips showed a lighter surface as compared to the other treatments (Fig. 6).

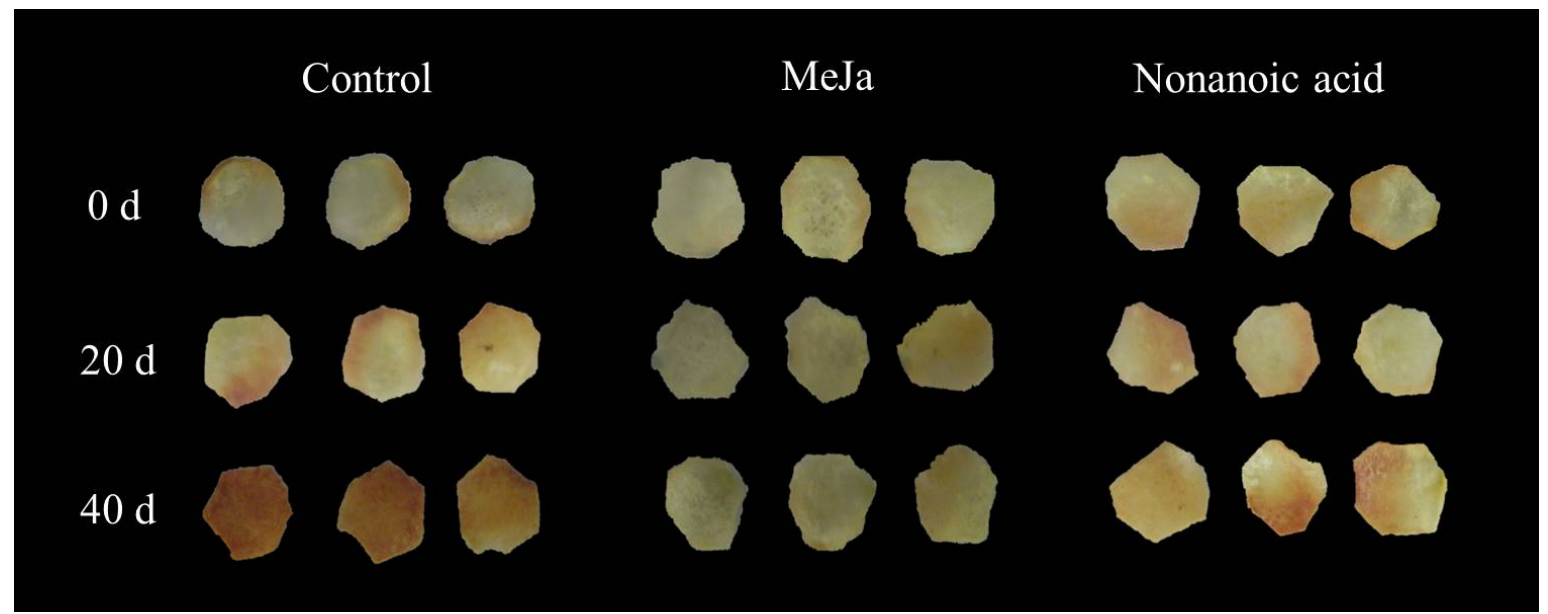

Figure 5. Visual analysis of the color of the sweet potato chips cultivar BRS Cuia, before and after storage, in response to control (CT), methyl jasmonate (MeJa) and nonanoic acid (NA) treatments.

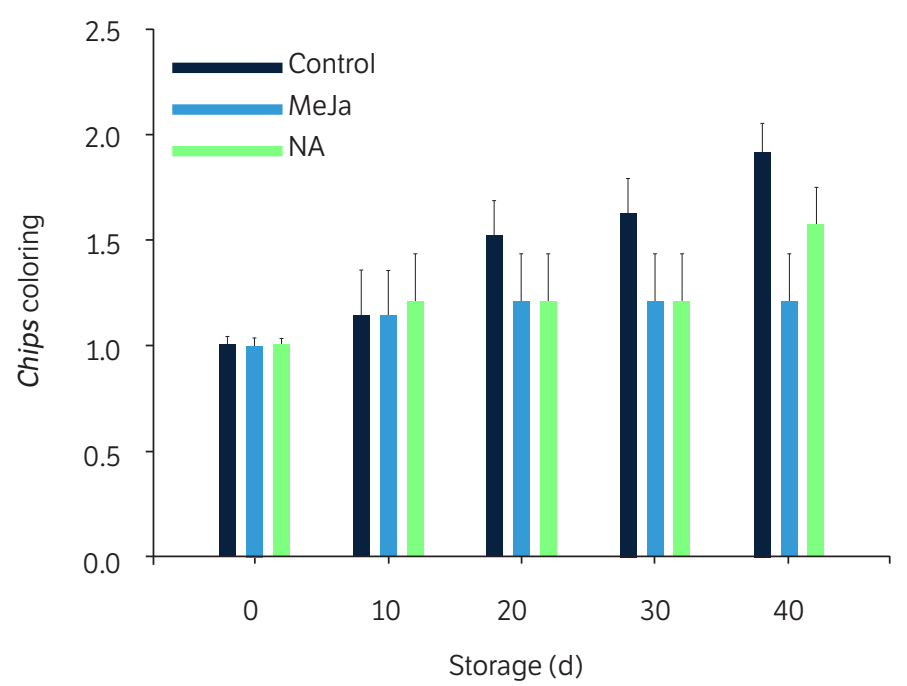

Figure 6. Color average based on browning scale in sweet potato chips responding to the application of sprout suppressors (control, $10 \mu \mathrm{mol} \cdot \mathrm{L}^{-1} \mathrm{MeJa}$ and $5 \mu \mathrm{mol} \cdot \mathrm{L}^{-1} \mathrm{NA}$ ) during storage for 40 days at temperature of $25^{\circ} \mathrm{C}$ and relative humidity $\pm 90 \%$.

Note. The data represent the mean \pm standard error $(n=5)$. 
The browning process displayed in sweet potato chips from both control and NA treatment is a response to RS accumulation, which causes losses of quality in fried chips. In addition, the incidence of sprouting may have led to increased activity of oxidative enzymes (Figs. 6 and 6b). This response is closely related to the results in this study that the sprouting percentage and sprouts length were higher in both control and NA roots (Figs. 2a and 2b) (Abbasi et al. 2015; Mckenzie et al. 2013). On the other hand, MeJa-treated roots showed a lighter color due to the lower accumulation of RS (Fig. 4b) as well as sprouting percentage and sprout length reductions (Figs. 2a and 2b).

The chips color is one of the most important aspects of quality evaluation and acceptance by the consumers. Darker chips get low acceptance due to the presence of disagreeable taste and low visual quality. Dark-colored chips may indicate that high levels of RS induced nonenzymatic browning (Araújo et al. 2016; Kumar et al. 2004), namely Maillard reaction, in which RS react with free amino acids, triggering the formation of dark compounds (Mckenzie et al. 2013).

Peroxidase and PPO activities increased linearly during storage for all treatments (Figs. 7a and 7b). However, MeJa-treated roots showed reduced POD activity until the $30^{\text {th }}$ day. On the other hand, the highest POD activity - with 9.5 AU. $\mathrm{min}^{-1} \cdot \mathrm{g}^{-1}$ protein - was observed in NA roots (Fig. 8a). Polyphenol oxidase activity increased in all treatments studied during storage, but control and NA roots showed higher activities (Fig. 8b). It is important to note that this response may be attributed to biodegradation reactions related to the processes of senescence in sweet potato roots (Lima et al. 2019; Tang et al. 2014).
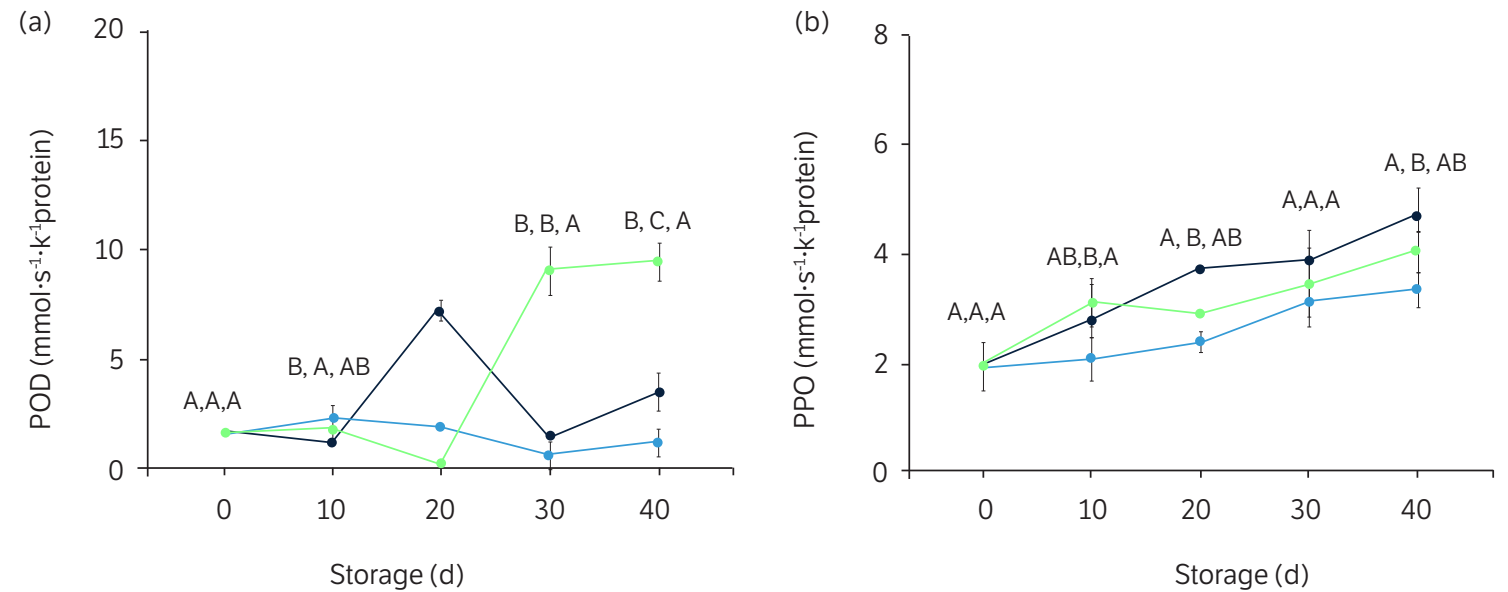

Figure 7. Peroxidase (a) and polyphenol oxidase (b) activity in sweet potato roots cultivar BRS Cuia responding to the application of sprout suppressors (control, $10 \mu \mathrm{mol} \cdot \mathrm{L}^{-1} \mathrm{MeJa}$ and $5 \mu \mathrm{mol} \cdot \mathrm{L}^{-1} \mathrm{NA}$ ) during storage for 40 days at temperature of $25^{\circ} \mathrm{C}$ and relative humidity $\pm 90 \%$.

Note. The data represent the mean \pm standard error $(n=5)$. Capital letters above lines indicate differences between treatments in each storage time, according to Tukey's test at $5 \%$ probability.

Principal component analysis (PCA) was performed to distinguish treatments and identify sproutingrelated variables in sweet potato roots. About $71.6 \%$ of the total variation was explained by the two first main components. All variables were positively correlated with PC1; except for RS, which was closely correlated with PC2 (Fig. 8). Conclusively, PC1 had differentiated sprouted from the non-sprouted roots. Based on that, it was observed that both control and NA-treated roots presented a high positive score for PC1. Such response reflects, therefore, the inability of NA in controlling sprouting. The acute angle between the variables associated with sprout growth and oxidative enzymes reveals a likely role of the oxidation of phenolic compounds by PPO and POD in triggering breaking dormancy in sweet potato roots, as previously observed in onion bulbs (Benkeblia and Selselet-Attou 1999). 


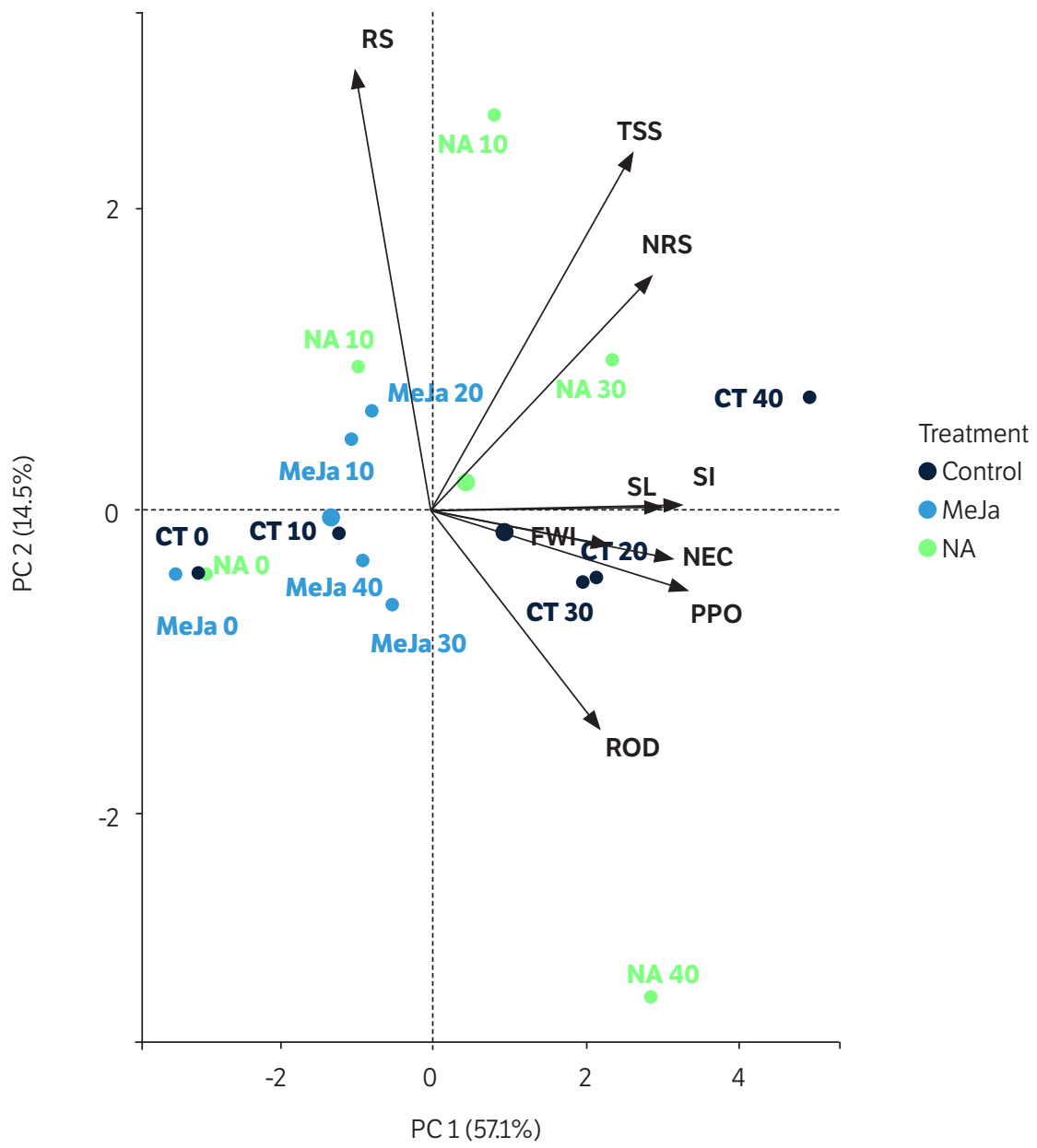

Figure 8. Biplot based on main component analysis obtained from quality data of fresh and processed sweet potato roots at $0,20,30$ and 40 days after application of control (CT), methyl jasmonate (MeJa) and nonanoic acid (NA) treatments.

Note. FWL: fresh weight loss; TSS: total soluble sugars; RS: reducing sugars; NRS: nonreducing sugars; SI: sprouting incidence; SL: sprouts length; POD: peroxidase; PPO: polyphenol oxidase; NED: nonenzymatic browning.

\section{CONCLUSION}

The application of MeJa reduces sprouting incidence and keeps the steady-state metabolic activity on roots during storage at room temperature, extending its shelf life and potential for commercialization. Moreover, MeJa treatment preserves the overall quality required for processing chips of sweet potatoes.

\section{AUTHORS' CONTRIBUTION}

Conceptualization: Veras M. L. M. and Finger F. L.; Methodology: Tello J. P. J., Veras M. L. M., Santos M. N. S., Araújo N. O. and Araújo F. F.; Data curation: Veras M. L. M. and Araújo N. O.; Software: Veras M. L. M and Araújo N. O.; Investigation: Tello J. P. J., Veras M. L. M., Santos M. N. S. and Araújo F. F.; Writing - Original draft: Veras M. L. M and Araújo N. O.; Writing - review \& editing: Tello J. P. J., Veras M. L. M., Santos M. N. S. and Finger F. L.; Validation: Araújo F. F.; Project administration: Finger F. L.; Funding acquisition: Finger F. L.; Supervision: Finger F. L. 


\section{DATA AVAILABILITY STATEMENT}

All dataset were generated and analyzed in the current study.

\section{FUNDING}

Conselho Nacional de Desenvolvimento Científico e Tecnológico

[https://doi.org/10.13039/501100003593]

Grant No. 302059/2018-0

Coordenação de Aperfeiçoamento de Pessoal de Nível Superior

[https://doi.org/10.13039/501100002322]

Finance Code 001

Fundação de Amparo à Pesquisa do Estado de Minas Gerais

[https://doi.org/10.13039/501100004901]

Grant No. PPM-00011-16

\section{ACKNOWLEDGMENTS}

This study was financed in part by the Coordenação de Aperfeiçoamento de Pessoal de Nível Superior - Brasil (CAPES) - Finance Code 001

\section{REFERENCES}

Abbasi, K. S., Masud, T., Ali, S., Khan, S. U., Mahmood, T. and Qayyum, A. (2015). Sugar-starch metabolism and antioxidant potential in potato tubers in response to different antisprouting agents during storage. Potato Research, 58, 361-375. https://doi.org/10.1007/ s11540-015-9306-4

Amoah, R. S., Landahl, S. and Terry, L. A. (2016). The timing of exogenous ethylene supplementation differentially affects stored sweetpotato roots. Postharvest Biology and Technology, 120, 92-102. https://doi.org/10.1016/j.postharvbio.2016.05.013

Araújo, T. H., Pádua, J. G., Spoto, M. H. F., Ortiz, V. D. G., Margossian, P. L., Dias, C. T. S. and Melo, P. C. T. (2016). Productivity and quality of potato cultivars for processing as shoestrings and chips. Horticultura Brasileira, 34, 554-560. https://doi.org/10.1590/ s0102-053620160415

Benjamin, N. D. and Montgomery, M. W. (1973). Polyphenol oxidase of Royal Ann cherries: purification and characterization. Journal of Food Science, 38, 799-806. https://doi.org/10.1111/j.1365-2621.1973.tb02079.x

Benkeblia, N. and Selselet-Attou, G. (1999). Effects of low temperatures on changes in oligosaccharides, phenolics and peroxidase in inner bud of onion (Allium cepa L.) during break of dormancy. Acta Agriculturae Scandinavica, Section B - Soil \& Plant Science, 49, 98-102. https://doi.org/10.1080/09064719950135605

Caetano, P. K., Mariano-Nasser, F. A. C., Mendonça, V. Z., Furlaneto, K. A., Daiuto, E. R. and Vieites, R. L. (2018). Physicochemical and sensory characteristics of sweet potato chips undergoing different cooking methods. Food Science and Technology, 38, 434-440. https://doi.org/10.1590/1678-457x.08217 
Cheema, M. U. A., Rees, D., Colgan, R. J., Taylor, M. and Westby, A. (2013). The effects of ethylene, 1-MCP and AVG on sprouting in sweetpotato roots. Postharvest Biology and Technology, 85, 89-93. https://doi.org/10.1016/j.postharvbio.2013.05.001

Ciriminna, R., Fidalgo, A., Ilharco, L. M. and Pagliaro, M. (2019). Herbicides based on pelargonic acid: Herbicides of the bioeconomy. Biofuels, Bioproducts and Biorefining, 13, 1476-1482. https://doi.org/10.1002/bbb.2046

Dhaif Allah, M. S., El-Adgham, F. I., El-Araby, S. M. and Ghoneim, I. M. (2018). Influence of jasmonic acid and chlorpropham treatments on sprouting, quality and storability of potato tubers during cold storage. Alexandria Journal of Agricultural Sciences, 63, $303-311$. https://doi.org/10.21608/alexja.2018.29387

DuBois, M., Gilles, K. A., Hamilton, J. K., Rebers, P. A. and Smith, F. (1956). Colorimetric method for determination of sugars and related substances. Analytical Chemistry, 28, 350-356. https://doi.org/10.1021/ac60111a017

El-Sayed, S. F., El-Helaly, M. A., Emam, M. S. and Abdel-Ghaffar, M. A. (2013). Effect of some post-cold storage treatments on shelf life of sweet potato roots. Journal of Horticultural Science and Ornamental Plants, 5, 160-170.

Finger, F. L., Santos, M. M. S., Araujo, F. F., Lima, P. C. C., Costa, L. C., França, C. F. M. and Queiroz, M. C. (2018). Action of essential oils on sprouting of non-dormant potato tubers. Brazilian Archives of Biology and Technology, 61, e18180003. https://doi.org/10.1590/1678-4324-2018180003

Foukaraki, S. G., Cools, K., Chope, G. A. and Terry, L. A. (2016). Impact of ethylene and 1-MCP on sprouting and sugar accumulation in stored potatoes. Postharvest Biology and Technology, 114, 95-103. https://doi.org/10.1016/j.postharvbio.2015.11.013

Gonçalves, C., Rodriguez-Jasso, R. M., Gomes, N., Teixeira, J. A. and Belo, I. (2010). Adaptation of dinitrosalicylic acid method to microtiter plates. Analytical Methods, 2, 2046-2048. https://doi.org/10.1039/c0ay00525h

Hajirezaei, M.-R., Börnke, F., Peisker, M., Takahata, Y., Lerchl, J., Kirakosyan, A. and Sonnewald, U. (2003). Decreased sucrose content triggers starch breakdown and respiration in stored potato tubers (Solanum tuberosum). Journal of Experimental Botany, $54,477-488$. https://doi.org/10.1093/jxb/erg040

Jia, B., Xu, L., Guan, W., Lin, Q., Brennan, C., Yan, R. and Zhao, H. (2019). Effect of citronella essential oil fumigation on sprout suppression and quality of potato tubers during storage. Food Chemistry, 284, 254-258. https://doi.org/10.1016/j.foodchem.2019.01.119

Kar, M. and Mishra, D. (1976). Catalase, peroxidase, and polyphenoloxidase activities during rice leaf senescence. Plant Physiology 57, 315-319. https://doi.org/10.1104/pp.57.2.315

Kumar, D., Singh, B. P. and Kumar, P. (2004). An overview of the factors affecting sugar content of potatoes. Annals of Applied Biology, 145, 247-256. https://doi.org/10.1111/j.1744-7348.2004.tb00380.x

Lee, B.-H. and Lee, Y.-T. (2017). Physicochemical and structural properties of different colored sweet potato starches. Starch Stärke, 69, 1600001. https://doi.org/10.1002/star.201600001

Lima, P. C. C., Santos, M. N. S., Araújo, F. F., Tello, J. P. J. and Finger, F. L. (2019). Sprouting and metabolism of sweet potatoes roots cv. BRS Rubissol during storage. Revista Brasileira de Ciências Agrárias, 14, e6204. https://doi.org/10.5039/agraria.v14i3a6204

Lulai, E. C., Orr, P. H. and Glynn, M. T. (1995). Natural suppression of sprouting in stored potatoes using jasmonates (U.S. Patent No. 5,436,226). U.S. Patent and Trademark Office.

Luo, D., Mu, T.-H., Sun, H. and Chen, J. (2020). Optimization of the formula and processing of a sweet potato leaf powder based beverage. Food Science \& Nutrition, 8, 2680-2691. https://doi.org/10.1002/fsn3.1555

Madonna, M., Caleb, O. J., Sivakumar, D. and Mahajan, P. V. (2018). Understanding the physiological response of fresh-cut cauliflower for developing a suitable packaging system. Food Packaging and Shelf Life, 17, 179-186. https://doi.org/10.1016/j.fpsl.2018.07.002

Mani, F., Bettaieb, T., Doudech, N. and Hannachi, C. (2014). Physiological mechanisms for potato dormancy release and sprouting: a review. African Crop Science Journal, 22, 155-174. 
McKenzie, M. J., Sowokinos, J. R., Shea, I. M., Gupta, S. K., Lindlauf, R. R. and Anderson, J. A. D. (2005). Investigations on the role of acid invertase and UDP-glucose pyrophosphorylase in potato clones with varying resistance to cold-induced sweetening. American Journal of Potato Research, 82, 231-239. https://doi.org/10.1007/BF02853589

McKenzie, M. J., Chen, R. K. Y., Harris, J. C., Ashworth, M. J. and Brummell, D. A. (2013). Post translational regulation of acid invertase activity by vacuolar invertase inhibitor affects resistance to cold induced sweetening of potato tubers. Plant, Cell \& Environment, 36 , 176-185. https://doi.org/10.1111/j.1365-3040.2012.02565.x

Ögel, Z. B., Yüzügüllü, Y., Mete, S., Bakir, U., Kaptan, Y., Sutay, D. and Demir, A.S., (2006). Production, properties and application to biocatalysis of a novel extracellular alkaline phenol oxidase from the thermophilic fungus Scytalidium thermophilum. Applied Microbiology and Biotechnology, 71, 853-862. https://doi.org/10.1007/s00253-005-0216-2

Pirbalouti, A. G., Sajjadi, S. E. and Parang, K. (2014). A review (research and patents) on jasmonic acid and its derivatives. Archiv der Pharmazie, 347, 229-239. https://doi.org/10.1002/ardp.201300287

Platonova, T. A. and Korableva, N. T. (1992). Changes in the Ultrastructure of Apical Meristem Cells in Potato during Transition from Dormancy to Growth. Prikladnaia Biokhimiia i Mikrobiologiia, 28, 760-770.

Platonova, T. A., Evsyunina, A. S. and Korableva, N. P. (2010). Changes in the plastid apparatus of apical meristem cells of potato tubers upon growth regulation with jasmonic acid. Applied Biochemistry and Microbiology, 46, 352-358. https://doi.org/10.1134/S0003683810030178

R Core Team (2020). R: A language and environment for statistical computing. Vienna: R Foundation for Statistical Computing.

Santos, M. N. S., Araujo, F. F., Lima, P. C. C., Costa, L. C. and Finger, F. L. (2020). Changes in potato tuber sugar metabolism in response to natural sprout suppressive compounds. Acta Scientiarum Agronomy, 42, 1807-8621. https://doi.org/10.4025/actasciagron.v42i1.43234

Sugri, I., Maalekuu, B. K., Kusi, F. and Gaveh, E. (2017). Quality and shelf-life of sweet potato as influenced by storage and postharvest treatments. Trends in Horticultural Research, 7, 1-10. https://doi.org/10.3923/thr.2017.1.10

Tang, J., Hu, K.-D., Hu, L.-Y., Li, Y.-H., Liu, Y.-S. and Zhang, H. (2014). Hydrogen sulfide acts as a fungicide to alleviate senescence and decay in fresh-cut sweetpotato. HortScience, 49, 938-943. https://doi.org/10.21273/HORTSCI.49.7.938

Teper-Bamnolker, P., Dudai, N., Fischer, R., Belausov, E., Zemach, H., Shoseyov, O. and Eshel, D. (2010). Mint essential oil can induce or inhibit potato sprouting by differential alteration of apical meristem. Planta, 232, 179-186. https://doi.org/10.1007/s00425-010-1154-5 Vaughn, S. F. and Spencer, G. F. (1991). Volatile monoterpenes inhibit potato tuber sprouting. American Potato Journal, 68, 821-831. https://doi.org/10.1007/BF02853856

Wang, C. Y. (1998). Methyl jasmonate inhibits postharvest sprouting and improves storage quality of radishes. Postharvest Biology and Technology, 14, 179-183. https://doi.org/10.1016/S0925-5214(98)00047-7 